\title{
Shopping in sanitised and un-sanitised spaces: Adding value to tourist experiences
}

Received (in revised form): 31 July 2006

\section{Sheena Westwood}

is a Senior Lecturer in Marketing and Research Methods at Cardiff School of Management, University of Wales Institute, Cardiff. Her research interests include tourist consumption behaviour, marketing and qualitative research enquiry. She has published work on gender issues in airline marketing, tourism branding and tourism experiences. Forthcoming work includes articles on the age-time-leisure paradox and a book chapter on projective methods in tourism research.

\begin{abstract}
Tourism is one of the world's largest industries and therefore understanding tourist consumption behaviour is important for those involved in aspects of conception, development and management of retail spaces. Far from being limited to the purchase of souvenirs and local crafts, tourist shopping has taken on new significance as a key motivator for travel, and more importantly as an integral part of the overall tourism experience. However, tourism experiences are subjective and inconsistent and are informed and enriched by a diversity of intrinsic and extrinsic influences. Through the individual experiences of participants in a wider study of tourism consumption, this paper considers tourist shopping experiences in sanitised and un-sanitised spaces. Excerpts from their narratives give insights into shopping behaviour to highlight the significance of the experiential and intangible values, and the complexity of individual expectations, aspirations, desires and insecurities that are played out within the spaces.
\end{abstract}

\section{Keywords:}

shopping, spaces, experience, narrative

Journal of Retail and Leisure Property (2006) 5, 281-291. doi:10.1057/palgrave.rlp.5100033

Sheena Westwood

Welsh Centre for Tourism Research Cardiff School of Management University of Wales Institute Colchester Avenue Cardiff CF23 9XR, UK Tel: + 44 (o) 2920417132 Fax: + 44 (o) 2920416930 E-mail: swestwood@uwic.ac.uk

\section{INTRODUCTION: SHOPPING SPACES AND TOURISM EXPERIENCES}

Already one of the world's largest industries which currently accounts for over 10 per cent of global GDP, and transports over $700 \mathrm{~m}$ travellers per year, tourism is predicted to grow by 4.2 per cent per annum between 2007 and 2016. ${ }^{1}$ Tourism centres on people, and tourism experiences involve discourses between people, places and products. Nor is the 
'tourism experience' a single entity, but it is comprised of microexperiences, each which is sensitive to a range of intrinsic and extrinsic influences, perceptions and constraints, and which consumers interpret and use in the creation of their individual tourism experiences. By definition, tourism indicates a transitory, fleeting visit during which many destinations, activities and attractions compete for tourists' attention, time and energy. With the notion of the 'experience economy' ${ }^{2}$ now firmly entrenched, and as companies redouble their efforts to compete in offering consumers bigger, better, more exciting, more experiential experiences than ever before, for anyone involved in retail and leisure planning, development and provision, an understanding of the interactional and experiential nature, and the diversity, of tourism consumption activities within the different shopping spaces is paramount.

Although shopping for souvenirs and gifts has always been an important tourism activity, shopping in its broadest sense continues to develop as a significant element of tourism, ${ }^{3,4}$ and is acknowledged as a highly significant economic contributor, indeed for many destinations such as Dubai and Hong Kong, it is now a key marketing proposition. Although research has shown that shopping was the second most popular activity for UK tourists abroad (the first being 'eating local food'), ${ }^{4}$ tourists do not necessarily set out with the intent to 'go' shopping, nor is shopping always primarily focused on purchase. During their wider experiences, tourists are likely to engage in a diversity of consumption encounters and rituals which involve interactions with vendors and service providers, and in its various guises, shopping involves more, or less, interaction depending on the nature of the space. Sanitised spaces are specifically designed for 'malling', that is, what Mikunda ${ }^{5}$ terms design that aims to induce a sense of familiarity and ease, and guide people through a complex to ensure their maximum exposure to 'merchandise, exhibits and services right for them'. These include specifically constructed and controlled tourist and leisure spaces such as theme parks, attractions, casinos, hotels and heritage centres, together with other purpose built commercial environments such as shopping malls, entertainment centres, department stores, transport hubs such as airports, sea and rail terminals and themed restaurants and cafes. Unsanitised spaces are those where shopping takes place in local, informal and less controlled environments such as streets, roadsides, local shops and markets, bazaars and beaches.

While there has been a steady increase in research on tourist shopping, there is a marked lack of attention on the experiential and socio-cultural aspects, indeed there is nothing that takes a qualitative, in-depth approach to examining the shopping experiences of individual consumers. ${ }^{6}$ While large scale, quantitative studies are effective in presenting broad, generalisable results, they lack the ability to reveal insights into individuality and idiosyncrasies of behaviour that are so valuable for those engaged in the development of competitively superior offerings. Through the narratives of participants in an interpretive study, this paper considers how different shopping spaces contribute to the experiential capital of tourism consumers. 


\section{SHOPPING AND TOURISM}

Timothy ${ }^{7}$ defines tourist shopping in two ways: as 'shopping tourism', where the prime reason for the trip is to shop, and 'tourism shopping', where shopping is just one of many other activities undertaken during the trip. Shopping tourism has increased significantly in the past few years, and within Europe through the changes to the fare structures and the facilitation of cheaper air travel, the low cost airlines have had marked consequences for the short haul, short stay travel markets and urban tourism. Impacts include the growth in the market through their network spread into hitherto difficult to access eurozone regions, and the change in consumer awareness, confidence and propensity to travel. Indeed, there are approximately 60 low cost airlines operating in Europe, who between them carried around $80 \mathrm{~m}$ passengers in $2004 .{ }^{4}$ Other driving factors for shopping tourism include the growth of shopping destinations, which range from 'factory outlet' shopping complexes such as Bicester Shopping Village in Oxfordshire, to the escalating numbers of destinations such as Dubai, Hong Kong, Singapore and New York where shopping has been developed as a significant element in their brand proposition.

The boundaries between other consumption practices and tourism are becoming indistinct, ${ }^{8-11}$, and for many, even though it is not the prime reason, shopping is an integral part of their holiday experience.

Consumption objects are available in virtually every place and space that tourists might encounter, and while some tourists might be primarily intent on purchase, others are more casual, browsing, window shopping and buying things as an adjunct to other activities, for less tangible reasons such as fun, interest, sensory stimulation, social contact and even vicarious purchase. ${ }^{12,13}$ Despite this, tourism-specific research interest in shopping has been slow to develop, and although it is on the increase, still the majority stems from researchers in North America and, more recently, some Pacific Asian countries. The main focus of these studies is on behavioural factors such as decisions, motivations and preferences, ${ }^{14-16}$ the development of profiles, typologies ${ }^{17-19}$ and destination-choice factors. ${ }^{3}$ Moreover, the predominant tendency is to consider shopping activities within a limited range of safe, controlled and sanitised retail spaces such as department stores, shopping malls and airports. ${ }^{20-22}$

\section{EXCHANGES AND ENCOUNTERS}

Although tourism is considered significant in encouraging cultural understanding and exchange, ${ }^{23,24}$ many tourists will not venture from their 'tourist bubble'. ${ }^{25}$ Culture shock is 'one of the most recognised difficulties encountered by travellers to foreign cultures', ${ }^{26}$ and relates to the challenges of coping with unfamiliar practices, stimuli, language, food and so on that tourists face in a different country and these have the capacity to cause anxiety, and may even lead to the avoidance of such situations by tourists ${ }^{27}$ who gravitate towards sanitised spaces. There, tourists feel insulated, prices of services and goods are fixed and tend to be clearly marked, employees are usually trained to give rigid, routinised and scripted performances in accordance with the company template, ${ }^{28,29}$ 
implicitly leaving little room, or need, for negotiation and interaction. Although there are still likely to be elements of culture shock, such consumption experiences are deemed safer, less threatening and risky, not only in terms of physical safety but also because of the predictability and familiarity of social conventions and etiquette.

For these reasons, however, other tourists will avoid sanitised spaces, and in search of 'difference' they will actively seek out opportunities to mix with local people and engage with them in a variety of 'authentic' ways, with shopping exchanges often providing the most opportunity for interaction and communication. In un-sanitised spaces, particularly outside of first world, Western countries, prices may not be marked or fixed, and the purchase of even a relatively low value souvenir can often involve quite a lengthy and complex ritual of bartering and haggling before a price is agreed: 'bartering is expected, in fact, it is customary in a souk' ${ }^{30}$ The interactions that take place during engagement in such encounters add intangible value and are often the most remembered parts of the experience, something summed up very succinctly by Sharjah souk trader Rouf. ${ }^{31}$

'In the big malls, you have someone who knows the price of the items - or the items already have a price tag on them... but most retailers here in the souk can tell you the story behind the items and their history. I know the background of every item in my shop, so you get more than the gift you buy, you have a story that goes with it'.

Nevertheless, while for some tourists, such experiences may be something to thoroughly enjoy and remember with fondness, particularly if the purchase is deemed to be a bargain; for others, such unfamiliar practices can be a daunting and stressful experience and are not without serious risk of fraud and danger. Some of the problems encountered include informal currency exchange, ${ }^{32}$ and the potential to be 'ripped off' with poor quality or counterfeit goods. For some consumers the lure of a 'bargain', however, is often to hard to resist, and such is the skill of the counterfeiters, and the power of desirable brand named goods, that many tourists actively seek out opportunities to purchase such goods. ${ }^{33-36}$

\section{RESEARCH METHODOLOGY}

This paper draws on the experiences of participants in a larger interpretive study of the relationships between tourists and objects within the context of their holiday experiences. It was an in-depth study which used autodriving (which effectively puts the participant in the driving seat, ${ }^{37,38}$ ) and participant created visual texts to create a reflexive and participantled research programme. Seven participants were purposefully chosen for the study, the critical elements being their willingness to be involved in some quite demanding and time-consuming activities. While gender was not a prime consideration, and efforts were made to recruit an equal number of men and women, five women and two men finally took part. The narratives of their experiences were recorded on tape during a series of conversations which were structured by the interpretation of images 
and artefacts of their actual, imagined idealised and constraint free holiday experiences. ${ }^{39}$ These included such things as destinations, travelling companions, accommodation, transport, products and myriad other symbolic representations.

\section{INTERPRETATIONS AND DISCUSSION}

Shopping is argued to be a dominantly female gendered activity, ${ }^{40-43}$ however, although gender was not a predominant consideration in this study, the participants' attitude to tourist shopping illustrates that while this may be the case for everyday shopping, tourist experiences are different, and shopping was enjoyed by both men and women. The study also exposes potential dangers in generalisations about behaviour. The gender divide is supported by Elizabeth's observation of men's dislike and intolerance with shopping (as in her wry reference to her husband as 'the Chancellor' - of the exchequer), stating that shopping is: 'more of a female thing, I do find that men in general are not interested in the shopping side of activities on holiday. I find them a bit of a dampening influence you could say and a brake...' In this study, however, not only does shopping feature to varying degrees as a significant element in the tourism experiences of all the female participants but also for both of the men. George, who admits that he normally is not keen on shopping, justifies his purchase of a watch because is on holiday - and thus, in a situation different to the 'everyday' '...I did buy an expensive watch, because I kept thinking, shall I treat myself on holiday? And in the end I bought one but I bought it in one of the malls'. He also infers here that he considers the purchases made within a sanitised mall as more safe and trustworthy than those made elsewhere. Dai, considers it fun and an integral part of the experience, and referring to his 'wandering' style of shopping, also remembers an extraordinary impulse buy which clearly brings fond memories:

\section{Dai}

'I think the fun would be buying wherever you are. Especially since a lot of this would be based in America I would think and they've got some terrific gear over there... I'm wearing Gap now, this is one of my favourite shirts, and Gap's an American company so l'd go and buy some when I was over there... it's a participatory thing. We don't go with any plans, we don't say we're going to go there to shop or try and get something, we're quite relaxed. If we see something we like we buy it. It's as simple as that. I mean last time we were in Florida there's the most exclusive shopping circles in America, with all the designer shops and everything, it's great, well my wife and I we walked into a jewellery shop and ended up buying an extremely expensive ring, well we didn't have any intention of buying one before we went on holiday, we just saw such a lovely ring and we both fell in love with it and we bought it but it wasn't part of the plan or anything. But it's nice to wander around 
the shops, that's all part of the holiday experience and everything isn't it?'

Like Dai, for Audrey, Jemima and Susannah shopping is relaxed and casual, a matter of drifting around and taking the opportunity of buying things that are perceived as bargains because they are cheaper than at home, or because they are different. Things that are indigenous to the host country have a special significance and their value is in the memories that they provoke and their ability to help re-create the experiences at home, thus they are considered to be worth the (inflated) price. Among the many purchases considered important as souvenirs are humorous and quirky mementos, objects and artefacts identical to those on sale at home, and in particular, food and drink for its power of sensory stimulation and recreation:

\section{Jemima}

'...we went to the spice market and bought spices there... that's what you're looking for is something different from what you can get at home. I always buy something when I'm abroad because ... I suppose I always think that the gold is better out there and cheaper as well. I like to buy something that is relevant to that area, so when we went to Prague, I bought some garnets, but they were quite expensive. And the other thing out there is amber, those are the two things that the shops in Prague seemed to have, all in the windows, everywhere. But I didn't find it cheap, but I did buy some.'

\section{Audrey}

'I really enjoy shopping anyway, but I do love the way on holiday you can take it at a slow pace and browse up and down and stop for coffee and things, it's much more a day of doing that as opposed to I need to go to the shops for whatever. And I'm quite into, when we go on holiday to a place and you sort of know the kind of thing you can get there, and so you sort of have a sensation, a feeling before ...l'd like to see if I can get whatever... like when we went to Italy for example I was just interested in Italian clothes and make up and things but my husband wanted to get cycling things. Shopping is quite a big element because we often think of that as an opportunity to get things that are good quality or the best price or whatever because you bought them from where they came from. That Russian doll there for example, ... you could get it here obviously, but that looks very Russian, but it really is as opposed to one you could just buy at home.

And also part of that is also the food shops, the food shopping thing ... we spend a lot of time browsing around because often abroad they often have small shops and those slightly more expensive or specialist and that's something we do quite a lot. Often it gives you a feeling of authenticity if you're having Italian food and you've got the balsamic 
vinegar that you bought in Sicily, that sort of makes it feel, you know, just sort of nicer and just reminds you of when you ate the same food on holiday.'

\section{A SERIOUS (AND RISKY) UNDERTAKING}

For Elizabeth and Rebecca, there are elements of risk as they each, in different ways, experience encounters that cause them some anxiety and stress. In contrast to the relaxed and random attitudes to shopping, both Rebecca and Elizabeth consider holiday shopping in a more serious light. Elizabeth talks here about having an 'aim' in relation to shopping, and explains how she always takes extra shopping bags to transport her 'trophies' home. For her, it is the unfamiliarity and unease with bartering, and uncertainty about the price she is paying that causes her to take three days to finally decide to purchase a rug from a bazaar in Qatar. Now as she reflects on the encounter, she recalls it with pleasure, and it is clear that the experience adds considerable intangible value to the object.

\section{Elizabeth}

'I would say that shopping was an important part of anywhere I go. I like to look at the shops, not necessarily purchase, make a huge purchase, but definitely suss out the, whatever's on offer in the shopping areas. We always pack two extra shopping bags so l've got plenty of room to bring home my trophies. I would say it would be nice to look for things that are a little bit different, special to that area, so for instance earlier in the year when we went to Qatar, I went with the specific intention of looking for a rug. To go to the old souks to see what it was like and make a few purchases I found very interesting, if somewhat stressful..., I'm a bit nervous in those sort of scenarios because I don't know the score, like if I'm bartering correctly or maybe I should do a bit more research before going. It does put me off because I'm not a good barterer, but we worked out our budget and stuck to that and I think we got a bargain although the whole procedure took 3 days. If it's something that I want and it's at a price I can afford and I don't obviously appear to be ripped off then I would buy it. I mean I look at that rug with great pleasure now and think that it was worth every penny. It brings back a lot of memories about the holiday ...'

Postmodern theory suggests that value is created in the actual consumption experience, ${ }^{44}$ and it is argued ${ }^{11}$ that increasingly consumption objects play a significant role in the enrichment and enhancement of the tourism experience and this is certainly borne out by Rebecca. Hong Kong has very strong associations as a shopping destination, ${ }^{45}$ and prior to a holiday there, Rebecca anticipated purchasing discounted and even counterfeit branded premium clothes and accessories such as handbags and shoes, and she uses the words 'mission', 'target', 'planning', 'list' and 'objectives', which reveal the dichotomous relationship between the fun of a holiday and the seriousness of obtaining 
the aspirational branded goods she so desires. To save time while there, she even visited the branch of a shop at home to try on clothes that she hoped to be able to purchase in Hong Kong, but was frustrated to find that the shop in Hong Kong had closed down.

The emotional overrides the rational for Rebecca and 'the game' has more serious overtones as expressed in her willingness to take risks in the pursuit of her 'goals'. Arellano ${ }^{33}$ notes that the main motivation for people purchasing counterfeit goods is satisfaction rather than outright deception, and in this excerpt, Rebecca indicates her awareness of the risks she is taking in purchasing counterfeit goods, which are overridden by the thrill of the chase:

\section{Rebecca}

'In Hong Kong the night markets are still the only place where you are going to get the fake branded stuff... things are recognizable, you will see bags with designer print but they won't necessarily have the designers label, so they are still sold in quite an open manner. But if you want the blatant proper branded fake goods it's almost sort of a sneaky operation, they've got a catalogue and they will take you to their store room which is maybe in one of the tower blocks near their stall and you go and pick what you want. My Mum wanted a fake designer bag so I was looking for this bag, and this woman said, to us' what are you looking for?... and then she said 'come with me', up into this block. I was a bit hesitant, I thought, 'oh, you might read about these where they get you into the office block and then they knock you on the head and steal your passport and your money and stuff'. So we went ... and it was stacked from the floor to the ceiling with bags of any brand and description. We actually went back this one night... as soon as the woman saw us she took us up to get a little stash. But of course, I had someone once mention to me about the moral dilemma, and I thought that I don't quite have an answer for that because I hadn't really thought about it'.

Ryan $^{46}$ argues that holidays provide an escape from social responsibility, and as Tom et al ${ }^{35}$ recognise, consumers of counterfeit goods often fail to acknowledge (or even realise) the social and economic consequences.

Rebecca's use of the word 'stash' - a word often associated with an illicit cache - is revealing, as she subconsciously indicates her awareness of the moral and ethical issues related to the deception, admitting that they have not been a conscious consideration.

\section{CONCLUSION}

This paper has explored the diversity of consumption encounters, the inclinations, emotions and behaviours of tourists, and introduced the notion of sanitised and un-santised shopping spaces. It captures the individual behaviours and considers them not as quantifiable, distanced, sanitised endeavours, but as a wide and nuanced range of experiences. For each of the participants, the sense of being somewhere different was a 
defining feature of their shopping experiences. With definite separation from the mundane and normal constraints and behaviours, holidays were considered a time to take time, to enjoy the freedom to browse, to choose, to immerse themselves and maybe indulge in bargain hunting, sometimes extravagant, sometimes on impulse, and in other cases with determination and precision planning. Interactions and encounters are integral to the tourist experience, and although the level of engagement and interaction varies, consumption encounters are a primary way for tourists to interact, and certainly despite feelings of unease and uncertainty at the time, afterwards it was the associated memories of the experiences in unsanitised spaces that participants recalled and which added pleasure.

Whereas un-sanitised spaces are enticing for some, others tourists may seek out, or seek to minimise or avoid opportunities for such encounters. Culture shock is something experienced in varying degrees by many tourists. Even in sanitised spaces, the conventions and etiquettes of commercial exchange can be initially daunting and something that tourists may seek to avoid, and there were both perceived and actual risks associated with some of the shopping experiences.

The relationship between tourists and tourist spaces is symbiotic, and tourism spaces are meeting grounds for people. They provide opportunities for focused commercial exchanges, but also, and more importantly, for relaxing, for browsing and making unplanned purchases which may be the reaction to extrinsic and/or marketing stimuli, but are also likely to be induced by intrinsic, personal motivations and impulses. Tourists (and other consumers) are not manageable, passive objects, rather they are active in the formation and the vitality of the places they visit, likewise, tourist spaces are fundamental to the creation of their experiences. Allport ${ }^{47}$ alerts retailers and planners to the need for greater understanding of consumer behaviour in order to succeed in today's highly competitive environment. He also refers to concerns regarding the 'sameness' of retail spaces and the threats from on-line retailers. Although the focus of this paper is on tourist experiences, it is argued that, with the convenience of on-line shopping for many items, 'going shopping' today is taking on a new significance, and is for many considered a pleasurable, leisure activity, and a way to spend free time, rather than being a constraint on it, and this where the point of difference lies.

In today's increasingly multi-cultural societies, and with the dynamic of people movement between places and spaces, for professionals involved with retail and leisure, recognition of 'interculturalness' ${ }^{26}$ and culture shock, are key considerations. Sanitised spaces that are increasingly experientially staged, managed and presented pre-packaged and 'micro-wave ready', however, leave little room for individuality and 'experiencing'. Shopping is not just one 'experience', but just like tourism it is a variegated and complex amalgam of micro-experiences which are shaped by people's own motivations and desires, and enriched and made memorable by emotion, interaction and sensory stimulation. Shopping spaces should be re-conceptualised as arenas where such experiences are created and with recognition of the power of the intangible values and the frisson of interactions, encounters and the unexpected. 


\section{References}

1. WTTC (2006). Blueprint for new tourism. World Travel and Tourism Council, available at http://www.wttc.org/blueprint/WTTCBlueprintFinal.pdf Accessed 30th July 2006

2. Pine, J. \& Gilmore, J. (1999). The Experience Economy, Harvard Business School Press, Boston.

3. Moscardo, G. (2004). Shopping as a destination attraction: an empirical examination of the role of shopping in tourists' destination choice and experience. Journal of Vacation Marketing 10(4), 294-307.

4. Mintel (2005). What the Brits Do on Holiday, Mintel Reports, Mintel International Limited.

5. Mikunda, C. (2004). Brand Lands, Hot Spots and Cool Spaces, Kogan Page, London.

6. Coles, T. (2004). Tourism, shopping, and retailing: an axiomatic relationship, in Lew A.A., Hall, C.M. and Williams, A.M. (eds), A Companion to Tourism, Blackwell, Oxford, pp. 360-373.

7. Timothy, D.J. (2005). Shopping, Tourism, Retail and Leisure, Channel View Publications, Clevedon.

8. Falk, P. \& Campbell, C. (1997). The Shopping Experience, Sage, London.

9. Shaw, G. \& Williams, A.M. (2004). Tourism and Tourism Spaces, Sage, London.

10. Coles, T. (2004). Tourism, shopping and retailing: an axioimatic relationship?, in Lew, A., Hall, C.M. \& Williams, A.M. (eds), A Companion to Tourism, Blackwell, Oxford, pp. 360-373.

11. Westwood, S. (2004). Narratives of tourism experiences: an interpretative approach to understanding tourist-brand relationships, $\mathrm{PhD}$ thesis, University of Wales.

12. Hirschman, E.C. (1980). Innovativeness, novelty seeking and consumer creativity. Journal of Consumer Research 7(December), 283-295.

13. Bellenger, D.N. \& Korgoankar, P. (1980). Profiling the recreational shopper. Journal of Retailing 58(Spring), 58-81.

14. Law, R. \& Au, N. (2000). Relationship modelling in tourism shopping: a decision rules induction approach. Tourism Management 21(3), 241-249.

15. Yuksel, A. (2004). Shopping experience evaluation: a case of domestic and international visitors. Tourism Management 25(6), 751-759.

16. Lehto, X.Y., Cai, L.A., O’Leary, J.T. \& Huan, T.C. (2004). Tourist shopping preferences and expenditure behaviours: the case of the Taiwanese outbound market. Journal of Vacation Marketing 10(4), 320-332.

17. Brengman, M., Geuens, M., Weijters, Smith, S.M. \& Swinyard, R. (2004). Segmenting Internet shoppers based on their web-usage rated lifestyle: a cross cultural validation, Working Paper, Ghent University, Faculty of Economics and Business Administration, available at http://www. FEB.UGent.be/fac/research/WP/Papers/wp_03_205.p.

18. Oh, Y.J.J., Cheng, C.K., Lehto, X.Y. \& O'Leary, J.T. (2004). Predictors of tourists shopping behaviour: examination of socio-demographic characteristics and trip typologies. Journal of Vacation Marketing 10(4), 308-319.

19. Littrell, M.A., Paige, R.C. \& Song, K. (2004). Senior travelers: tourism activities and shopping behaviours. Journal of Vacation Marketing 10(4), 348-362.

20. Johnson, S. \& Howard, E. (1990). The leisure market: Consumer choice and consumer activity, in Howard, E. (ed.), Leisure and Retailing, Longman, Harlow, pp. 25-42.

21. Jackson, E.L. (1991). Shopping and leisure: implications of West Edmonton Mall for leisure research. The Canadian Geographer 35(3), 280-289.

22. Lehtonen, T.K. \& Mäenpää, P. (1997). Shopping in the East Centre Mall, in Falk P. and Campbell C. (eds), The Shopping Experience, Sage, London, pp. 136-165.

23. Ap, J. (2001). Tourists perceptions of their level of contact with host residents. Tourism Pacific Review 5(1), 51-58.

24. McKercher, B. \& So-Ming, B.C. (2001). Cultural difference and participation in cultural tourism. Pacific Tourism Review 5(1), 23-32.

25. Judd, D.P. (1999). Constructing the tourist bubble, in Judd, D.P. and Fainstein, S.S. (eds.), The Tourist City, Yale University Press, New Haven, CT, pp. 35-54.

26. Reisinger, Y. \& Turner, L.W. (2003) Cross-Cultural Behaviour in Tourism, ButterworthHeinemann, Oxford.

27. Ventola, E. (1987) The Structure of Social Interaction, A Systematic Approach to the Semiotics of Service Encounters, Frances Pinter, London.

28. Hofstede, G. (2001) Culture's Consequences: Comparing Values, Behaviours, Institutions and Organizations Across Nations, 2nd edn, Sage, Thousand Oaks.

29. Ritzer, G. (2000) The McDonaldization of Society, Sage, London.

30. Anon (2006). Feeling Blue. al nawras, (in flight magazine of Air Arabia) May-June, 28.

31. Rouf (2006). Cited in Anon. Feeling Blue, (in flight magazine of Air Arabia), May-June, 28-29.

32. Shaw, B.J. \& Shaw, G. (1998). Sun, sand and sales, enclave tourism and local entrepreneurship in Indonesia. Current Issues in Tourism 2(1), 68-81. 
33. Arellano, R. (1994). Informal-underground retailers in less-developed countries: an exploratory research from a marketing pint of view. Journal of Macromarketing 14, 21.

34. Wee, C.-H., Tan, S.-J. \& Cheok, K.-H. (1995). Non-price determinants of intention to purchase counterfeit goods. International Marketing Review 12(6), 19-46.

35. Tom, G., Garibaldi, B., Zeng, Y. \& Pilcher, J. (1998). Consumer demand for counterfeit goods. Psychology and Marketing 15(5), 405-421.

36. Abers-Miller, N.D. (1999). Consumer misbehaviour: why people buy illicit goods. Journal of Consumer Marketing 16(3), 273-288.

37. Heisley, D.D. \& Levy, S.J. (1991). Autodriving: A photoelicitation technique. Journal of Consumer Research 18, 257-272.

38. Westwood, S. (2006). What lies beneath? Using creative, projective and participatory techniques in qualitative tourism inquiry, in Ateljevic, I., Morgan, N. and Pritchard, A. (eds.), The Critical Turn in Tourism Studies: Innovative Research Methodologies, Elsevier, Oxford, in press.

39. Gabriel, Y. (1995). The unmanaged organization, stories, fantasy, subjectivity. Organization Studies 16(3), 477-501.

40. Anderson, L. \& Littrell, M.A. (1995). Souvenir purchase behaviour of women tourists. Annals of Tourism Research 22(2), 328-348.

41. Anderson, L. \& Littrell, M.A. (1996). Group profiles of women as tourists and purchasers of souvenirs. Family and Consumer Sciences Research Journal 25(1), 28-56.

42. Campbell, C. (1997). Shopping, pleasure and the sex war, in Falk, P. and Campbell, C. (eds), The Shopping Experience, Sage, London, pp. 166-176.

43. Cockburn-Wootten, C. (2002). Gender, grocery shopping and the discourse of leisure PhD Thesis, University of Wales.

44. Firat, F.A. (1991). The consumer in postmodernity. Advances in Consumer Research 18, $70-76$.

45. Wong, J. \& Laws, R. (2003). Differences in shopping satisfaction levels: a study of tourists in Hong Kong. Tourism Management 24, 401-410.

46. Ryan, C. (2002) (ed.) The Tourist Experience, Continuum, London.

47. Allport, D. (2006). The UK high street: current issues and their implications. Journal of Retail and Leisure Property 5(1), 2-16. 